\title{
Copper-Catalyzed Ring Expansion of Vinyl Aziridines under Mild Conditions
}

\author{
Eleonora Tosi \\ Kim Spielmann \\ Renata Marcia de Figueiredo*(i) \\ Jean-Marc Campagne*
}

ICGM, Univ Montpellier, CNRS, ENSCM, Montpellier, France

jean-marc.campagne@enscm.fr

renata.marcia_de_figueiredo@enscm.fr

In expression of our respect to Professor Barry M. Trost on the occasion of his $80^{\text {th }}$ birthday.

Published as part of the Cluster

The Power of Transition Metals: An Unending Well-Spring of New Reactivity
Received: 29.10.2020

Accepted after revision: 08.12.2020

Published online: 05.01 .2021

DOI: 10.1055/s-0040-1706007; Art ID: st-2020-k0569-c

Abstract Vinyl aziridines are versatile starting materials toward ringexpansion transformations. Such processes are widely used to give various medium or larger N-heterocycles of synthetic interest. This letter describes a copper-catalyzed ring expansion of vinyl aziridines to 3-pyrrolines by using a $\mathrm{Cu}(\mathrm{I})$ salt $\left[(\mathrm{CuOTf})_{2}\right.$.toluene or $\left.\mathrm{Cu}(\mathrm{MeCN})_{4} \cdot \mathrm{PF}_{6}\right]$. In particular, this transformation occurs under mild conditions (THF, rt).

Key words ring expansion, vinyl aziridines, pyrrolines, copper catalysis, heterocycles

Ring expansion of small-sized carbo- and heterocycles is among the most widely used transformations toward medium (or larger) carbo- and heterocycles. ${ }^{1}$ Due to the presence of both a highly strained three-membered heterocycle and an activated double bond, vinyl aziridines are an extraordinary source of reactivity, and are therefore valuable building blocks in organic synthesis. ${ }^{2-4}$ Consequently, we have been interested in exploring possibilities for performing ring-expansion processes with vinyl aziridines under mild and practical conditions toward novel useful building blocks. Moreover, N-heterocycles are highly valued and widely used in medicinal chemistry, revealing much promise for industrial purposes. ${ }^{5}$

Building on our previous work in the area of palladiumcatalyzed [3+2]-cycloadditions of vinyl aziridines 1 with cyclic sulfoxyimines, ${ }^{4}$ we were drawn to the potential use of silyl enol ethers $\mathbf{2}$ in the presence of Lewis acids to form the corresponding five-membered lactams 3 (Scheme 1) bearing a quaternary center.

When the reaction was attempted with model compound 1a and the silyl enol ether 2a in the presence of 5 mol\% of $\mathrm{Cu}(\mathrm{OTf})_{2}$ at room temperature in dichloromethane, the expected compound 3a could not be observed in the

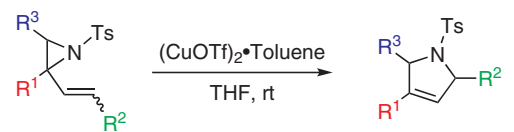

Pyrrolines synthesis

O Practical procedure

O Mild reaction conditions

O Short reaction time up to $94 \%$ yield

Scheme 1 Envisaged reactions of vinyl aziridines 1 with silyl enol ethers 2

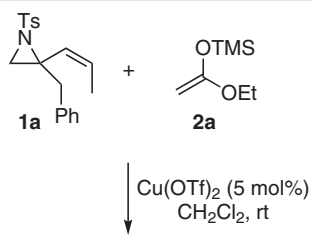

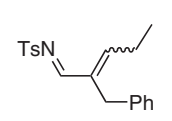

$4 a$

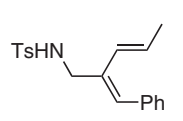

$5 a$

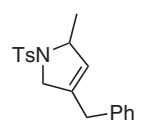

$6 a$ $10-20 \%$ yield

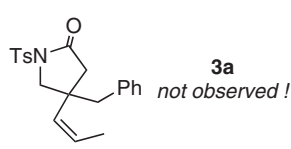

Scheme 2 Attempted reaction of vinyl aziridine $\mathbf{1}$ a with silyl enol ether 2a under copper catalysis

crude material. Instead, along with the rather predictable elimination compounds $\mathbf{4 a}$ and $\mathbf{5 a}$, pyrroline $\mathbf{6 a}$ was isolated from the reaction mixture in low yields (10-20\%) (Scheme 2). 
The copper-catalyzed ring expansion of vinyl aziridines to 3-pyrrolines is a known reaction, originally described by Njardarson and co-workers in 2008 (Scheme 3). ${ }^{6}$ However these reactions required the presence of an unusual copper complex, bis(hexafluoroacetylacetonato)copper [Cu(hfa(ac) $)_{2}$ ], under relatively harsh conditions (toluene, $150{ }^{\circ} \mathrm{C}$ ) ${ }^{7}$ As shown in Scheme 3, various substituted 3-pyrrolines could be efficiently obtained under these reaction conditions; the reaction mechanism was also unveiled. ${ }^{6 c}$

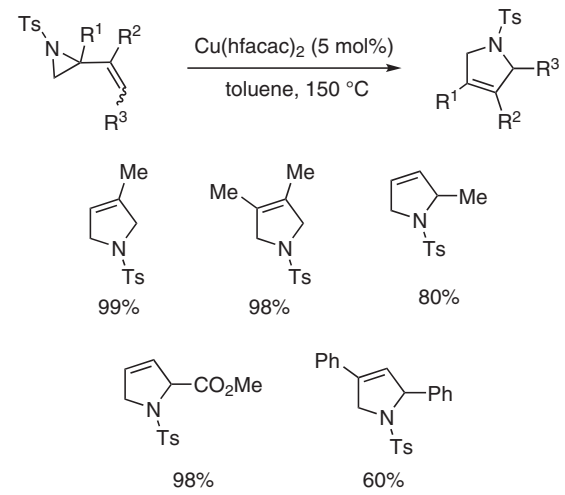

Scheme 3 Some examples of vinyl aziridine rearrangements under Njardarson's conditions ${ }^{6 a}$

The very mild conditions (Scheme 2) in which 6a was formed in our reaction prompted us to reinvestigate the reaction conditions (Table 1) towards the exclusive, or at least, main formation of pyrroline $\mathbf{6 a}$. Interestingly, in the absence of silyl enolate $\mathbf{2 a}$, the pyrroline $\mathbf{6 a}$ was not observed (Table 1, entry 2). Suspecting an in situ $\mathrm{Cu}(\mathrm{II}) \rightarrow \mathrm{Cu}(\mathrm{I})$ reduction in the reaction process, ${ }^{8}$ we investigated the use of $\mathrm{Cu}(\mathrm{I})$ salts in the absence of silyl enolate $2 \mathbf{a}$. Whereas various $\mathrm{Cu}(\mathrm{I})$ salts proved unsuccessful in catalyzing the reaction (entries 3-5), we were delighted to observe the clean formation of $\mathbf{6 a}$ in the presence of $10 \mathrm{~mol} \%$ of (CuOTf) $)_{2}$ toluene (entry 6 ) at room temperature in THF. ${ }^{9}$ To exclude the possibility of an organic acid-catalyzed transformation, we ran a trial in the presence of $5 \mathrm{~mol} \%$ of TFA; in this case, no reaction was observed (entry 7 ).

After optimizing of the basic rearrangement reaction with vinyl aziridine 1a, we examined its general scope. For

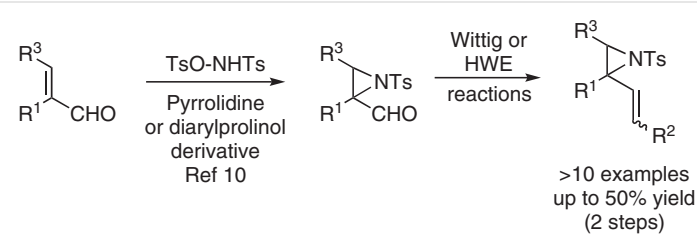

Scheme 4 Synthesis of vinyl aziridines $\mathbf{1}$. For additional details, see Supporting Information.
Table 1 Pyrroline 6a Synthesis from Vinyl Aziridine 1a: Optimization Study

\begin{tabular}{lllll}
\hline Entry & Solvent & Cat. (5 mol\%) & $(\mathbf{4 a}+\mathbf{5 a}) / \mathbf{6 a} \mathbf{a}^{\mathrm{b}}$ & Yield (\%) of 6a \\
\hline $1^{\mathrm{c}}$ & $\mathrm{CH}_{2} \mathrm{Cl}_{2}$ & $\mathrm{Cu}(\mathrm{OTf})_{2}$ & $70: 30$ & 10 \\
2 & $\mathrm{CH}_{2} \mathrm{Cl}_{2}{ }^{\mathrm{d}}$ & $\mathrm{Cu}(\mathrm{OTf})_{2}$ & $100: 0$ & - \\
3 & $\mathrm{THF}$ & {$[(i-\mathrm{Pr}) \mathrm{CuCl}]$} & $\mathrm{NR}$ & - \\
4 & $\mathrm{THF}$ & {$\left[\left(\mathrm{Ph}_{3} \mathrm{P}\right)_{3} \mathrm{CuF}\right]$} & $\mathrm{NR}$ & - \\
5 & $\mathrm{THF}$ & $\mathrm{CuTC}^{\mathrm{e}}$ & $\mathrm{NR}$ & - \\
6 & $\mathrm{THF}$ & $(\mathrm{CuOTf})_{2} \cdot$ toluene & $<5:>95$ & 60 \\
7 & $\mathrm{THF}$ & $\mathrm{TFA}$ & $\mathrm{NR}$ & - \\
\hline
\end{tabular}

a Reactions conditions: 1a $(0.05 \mathrm{mmol})$, catalyst $(5 \mathrm{~mol} \%)$, solvent (0.5 $\mathrm{mL})$, rt, argon atmosphere, $12 \mathrm{~h}$.

${ }^{b}$ Determined by ${ }^{1} \mathrm{H}$ NMR of the crude product.

c With silyl enolate $2 a$ ( 1.5 equiv).

d Or THF.

e $\mathrm{NR}=$ no reaction

${ }^{\mathrm{f}} \mathrm{TC}=$ thiophene-2-carboxylate.

this purpose, a small collection of vinyl aziridines 1 were prepared by following a sequence involving an organocatalyzed aziridination/Wittig reaction (Scheme 4). ${ }^{6,10}$ The expected substrates needed for the ring-expansion transformation were obtained in moderate-to-good yields.

As shown in Scheme 5, various mono- and disubstituted pyrrolines $\mathbf{6}$ were isolated in good yields. In the presence of both $R^{1}$ and $R^{2}$ groups in the starting vinyl aziridine, pyrrolines $\mathbf{6 a}$ and $\mathbf{6 b}$ were obtained in yields of 60 and 33\%, respectively. Notably, no reaction was observed when an electron-withdrawing group $\left(\mathrm{R}^{2}=\mathrm{CO}_{2} \mathrm{Et}\right.$; compound $\left.\mathbf{6 c}\right)$ was present, and for which Njardarson's conditions are efficient. $^{6}$ From monosubstituted aziridines $\mathbf{1 d}-\mathbf{g}$, the corresponding pyrrolines $\mathbf{6 d - g}$ were obtained in yields of $60-$ $94 \%$. Of note, the presence of functionalized side-chains was well tolerated $(\mathbf{6 g}$ and $\mathbf{6 j})$. The rearrangement of vinyl aziridine 1d was also performed at a $1 \mathrm{mmol}$ scale (as opposed to $0.14 \mathrm{mmol}$ ) to give the expected pyrroline $\mathbf{6 d}$ in a comparable isolated yield of $83 \%$. The ring expansion of vinyl aziridines $\mathbf{1 h}-\mathbf{j}$ with substituents at the $\mathrm{R}^{3}$ position was next investigated. In this case, pyrrolines $\mathbf{6 h}-\mathbf{j}$ were formed in moderate to good yields of $40-57 \%$. From these results, we can deduce that hindrance around the NTs functional group (the $\mathrm{R}^{2}$ and $\mathrm{R}^{3}$ groups) has a deleterious effect on the ring-expansion process, as the expected compounds were isolated in lowers yields $(<60 \%)$. In these cases, the reactions were complete according to TLC monitoring, but were accompanied by the formation of unidentified byproducts. This trend was reinforced when substrate $\mathbf{1 k}$ was submitted to the ring-expansion conditions, as none of the trisubstituted pyrroline $\mathbf{6 k}$ was formed. In contrast, pyrrolines monosubstituted at $\mathrm{R}^{1}$ were obtained in excellent yields $(\leq 94 \%)$. Interestingly, $\mathrm{Cu}(\mathrm{MeCN})_{4} \cdot \mathrm{PF}_{6}$ could also be used as catalyst for the synthesis of $\mathbf{6 b}, \mathbf{6 d}$, and $\mathbf{6 i}$, affording similar yields (32, 90, and $40 \%$, respectively). 


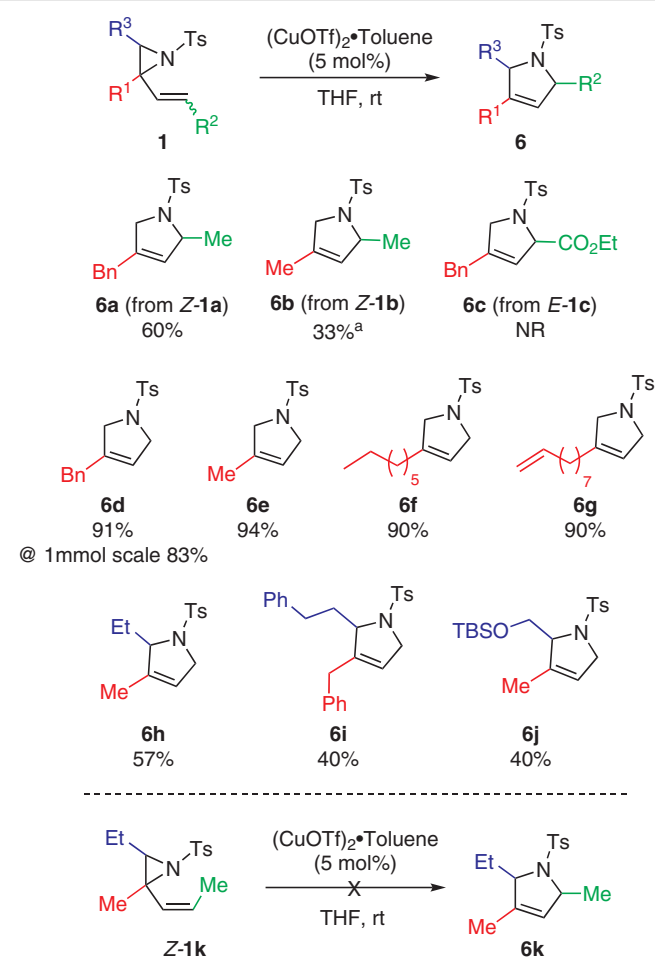

Scheme 5 Scope of the rearrangement of vinyl aziridines $\mathbf{1}$. Reagents and conditions: 1 (0.14 mmol), (CuOTf) $)_{2}$ toluene (5 mol\%), THF (0.7 $\mathrm{mL}$ ), rt, $2 \mathrm{~h}$. Isolated yields after purification by silica gel column chro-

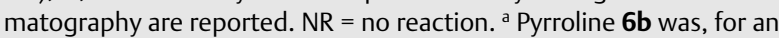
unknown reason, very difficult to purify.

Thanks to an easy access to 2-substituted vinyl cyclopropanes, ${ }^{11}$ a related reaction of the vinylcyclopropane 7 was next attempted under the same reaction conditions, but with no success (Scheme 6). The rearrangement of vinyl epoxides had been previously reported by Njardarson $\left[\mathrm{Cu}(\mathrm{hfacac})_{2}(5 \mathrm{~mol} \%)\right.$, toluene, $\left.150{ }^{\circ} \mathrm{C}\right] .{ }^{6 \mathrm{~d}}$ We therefore attempted a rearrangement of vinyl epoxide $\mathbf{9}$ in the presence of $(\mathrm{CuOTf})_{2}$ at room temperature, but the reaction led to an intractable mixture of products, and dihydropyran $\mathbf{1 0}$ could not be isolated.

The mild conditions used in this transformation (THF, rt) prompted us to check the reaction stereospecificity.

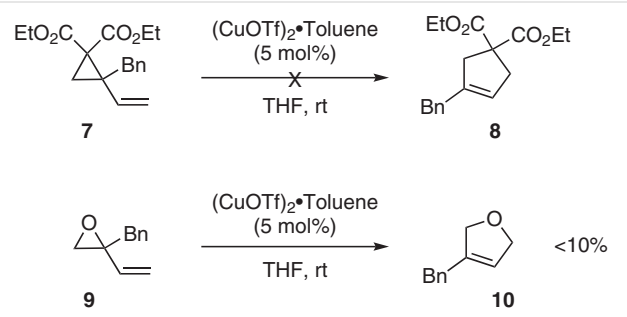

Scheme 6 Attempted copper-catalyzed rearrangements of vinylcyclopropane $\mathbf{7}$ and epoxide $\boldsymbol{9}$
Starting from the enantiomerically enriched vinyl aziridine (Z)-1a (80\% ee), ${ }^{10}$ the corresponding pyrroline $\mathbf{6 a}$ was obtained in $62 \%$ yield in a racemic form (Scheme 7).

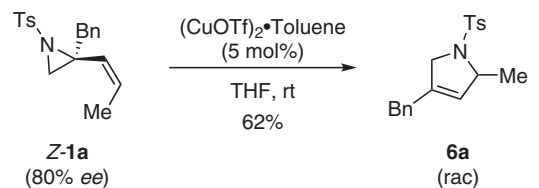

Scheme 7 Rearrangement of enantiomerically enriched vinyl aziridine (Z)-1a

These results, including the racemization of enantiomerically enriched vinyl aziridines, are in full accordance with Njardarson's observations. Mechanistic studies performed by Njardarson and co-workers highlighted a copper(I) insertion into the $\mathrm{C}-\mathrm{N}$ bond to give an allylcopper intermediate, ultimately leading, to the pyrroline $\mathbf{6}$ after reductive elimination (Scheme 8; left-hand pathway). ${ }^{6 c}$ An alternative mechanistic scenario (Scheme 8; right-hand pathway) involving copper coordination and subsequent heterolytic rupture of the $\mathrm{C}-\mathrm{N}$ bond, followed by the attack of the $N$-tosyl anion, cannot be totally excluded under our reaction conditions.

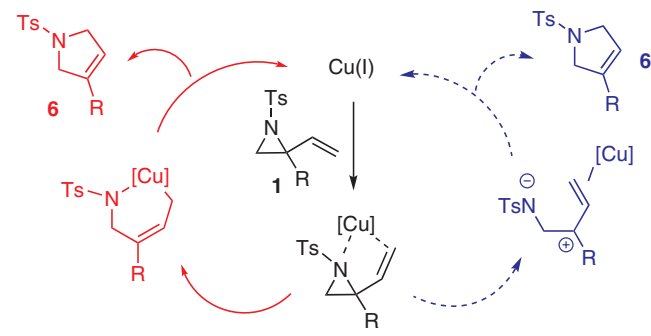

Scheme 8 Proposed mechanistic scenarios

These mechanistic insights prompted us to test the use of palladium salts in these ring-opening aziridine reactions. In a model reaction with (Z)-1a, we eventually found that, under aza-Wacker conditions, ${ }^{12}$ the corresponding pyrrole $\mathbf{1 1}$ could be obtained in an unoptimized 50\% yield (Scheme 9)..$^{13}$

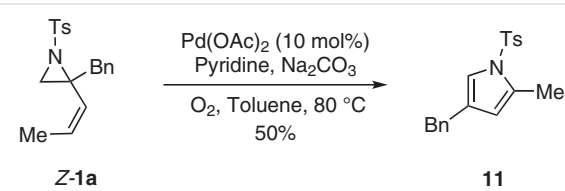

Scheme 9 Aza-Wacker-type rearrangement of (Z)-1a

In conclusion, we have developed a practical protocol ${ }^{14}$ for the synthesis of 3-substituted pyrrolines from accessible vinyl aziridines. The ring-expansion process takes place under $\mathrm{Cu}(\mathrm{I})$ catalysis. In particular, mild conditions (THF, rt) are sufficient to accomplish the rearrangements. In the 
presence of $\mathrm{R}^{2}$ and $\mathrm{R}^{3}$ groups (steric hindrance around the NTs functionality), yields ranged from 33 to $60 \%$, whereas 3-pyrrolines $\left(\mathrm{R}^{2}=\mathrm{R}^{3}=\mathrm{H}\right)$ were isolated in higher yields (>90\%). Further investigations will be carried in an attempt to understand the correlation (if any) between conversion and steric encumbrance, and also to broaden the actual scope. The present procedure might be an efficient method for the synthesis of 3-pyrrolines, which are useful building blocks in both organic and medicinal chemistry. Moreover, the Wacker-type reactions disclosed are currently under investigation.

\section{Funding Information}

This work was supported by the Ecole Nationale Supérieure de Chimie de Montpellier (ENSCM) (K.S.), the ANR (ANR- 18-CE07-003801; E.T.), and the CNRS (Centre National de la Recherche Scientifique). Brigita Mudráková is kindly thanked for her help with the synthesis of some aziridines.

\section{Supporting Information}

Supporting information for this article is available online at https://doi.org/10.1055/s-0040-1706007.

\section{References and Notes}

(1) For selected reviews, see: (a) Donald, J. R.; Unsworth, W. P. Chem. Eur. J. 2017, 23, 8780. (b) Clarke, A. K.; Unsworth, W. P. Chem. Sci. 2020, 11, 2876. (c) Mack, D. J.; Njardarson, J. T. ACS Catal. 2013, 3, 272. (d) Huang, C.-Y.; Doyle, A. G. Chem. Rev. 2014, 114, 8153. (e) Dauban, P.; Malik, G. Angew. Chem. Int. Ed. 2009, 48, 9026.

(2) For a review, see: Ohno, H. Chem. Rev. 2014, 114, 7784.

(3) For some selected recent publications see: (a) Kaldas, S. J.; Kran, E.; Mück-Lichtenfeld, C.; Yudin, A. K.; Studer, A. Chem. Eur. J. 2020, 26, 1501. (b) Zhao, Q.-Q.; Zhou, X.-S.; Xu, S.-H.; Wu, Y.-L.; Xiao, W.-J.; Chen, J.-R. Org. Lett. 2020, 22, 2470. (c) Wan, S.-H.; Liu, S.-T. Tetrahedron 2019, 75, 1166. (d) Singh, D.; Ha, H.-J. Org. Biomol. Chem. 2019, 17, 3093. (e) Wu, A.; Feng, Q.; Sung, H. H. Y.; Williams, I. D.; Sun, J. Angew. Chem. Int. Ed. 2019, 58, 6776. (f) Zhu, C.-Z.; Feng, J.-J.; Zhang, J. Chem. Commun. 2018, 54, 2401. (g) Jiang, F.; Yuan, F.-R.; Jin, L.-W.; Mei, G.-J.; Shi, F. ACS Catal. 2018, 8, 10234; and references cited therein.

(4) (a) Spielmann, K.; Tosi, E.; Lebrun, A.; Niel, G.; van der Lee, A.; de Figueiredo, R. M.; Campagne, J.-M. Tetrahedron 2018, 74, 6497. (b) Spielmann, K.; van der Lee, A.; de Figueiredo, R. M.; Campagne, J.-M. Org. Lett. 2018, 20, 1444.

(5) (a) Taylor, R. D.; MacCoss, M.; Lawson, A. D. J. J. Med. Chem. 2014, 57, 5845. (b) Vitaku, E.; Smith, D. T.; Njardarson, J. T. J. Med. Chem. 2014, 57, 10257. (c) Aldeghi, M.; Malhotra, S.; Selwood, D. L.; Chan, A. W. E. Chem. Biol. Drug Des. 2014, 83, 450.
(6) (a) Brichacek, M.; Lee, D.; Njardarson, J. T. Org. Lett. 2008, 10, 5023. (b) Brichacek, M.; Villalobos, M. N.; Plichta, A.; Njardarson, J. T. Org. Lett. 2011, 13, 1110. (c) Mack, D. J.; Njardarson, J. T. Chem. Sci. 2012, 3, 3321. (d) Batory, L. A.; McInnis, C. E.; Njardarson, J. T. J. Am. Chem. Soc. 2006, 128, 16054.

(7) For thermal rearrangements of 2-vinyl aziridines, see: (a) Mente, P. G.; Heine, H. W. J. Org. Chem. 1971, 36, 3076. (b) Pommelet, J. C.; Chuche, J. Can. J. Chem. 1976, 54, 1571. (c) Borel, D.; Gelas-Mialhe, Y.; Vessière, R. Can.J. Chem. 1976, 54, 1590. (d) For a [4+1] access to 3-pyrrolines, see also: Wu, Q.; Hu, J.; Ren, X.; Zhou, J. Chem. Eur. J. 2011, 17, 11553.

(8) (a) Kobayashi, Y.; Taguchi, T.; Morikawa, T.; Tokuno, E.; Sekiguchi, S. Chem. Pharm. Bull. 1980, 28, 262. (b) Ferraris, D.; Young, B.; Cox, C.; Drury, W. J. III.; Dudding, T.; Leckta, T. J. Org. Chem. 1998, 63, 6090. (c) Pagenkopf, B. L.; Krüger, J.; Stojanovic, A.; Carreira, E. M. Angew. Chem. Int. Ed. 1998, 37, 3124; See also the Njardarson mechanistic studies in reference 6 (c).

(9) After a short screening of solvents (e.g., THF, $\mathrm{CH}_{2} \mathrm{Cl}_{2}$, toluene, hexane), THF was chosen to perform the transformation.

(10) Desmarchelier, A.; Pereira de Sant'Ana, D.; Terrasson, V.; Campagne, J.-M.; Moreau, X.; Greck, C.; de Figueiredo, R. M. Eur. J. Org. Chem. 2011, 4046.

(11) Terrasson, V.; van der Lee, A.; de Figueiredo, R. M.; Campagne, J.M. Chem. Eur. J. 2010, 16, 7875.

(12) Bao, X.; Wang, Q.; Zhu, J. Angew. Chem. Int. Ed. 2018, 57, 1995.

(13) For related reactions involving Pt- or Au-catalyzed ring expansions of alkynyl aziridines, see: (a) Yoshida, M.; Easmin, S.; AlAmin, M.; Hirai, Y.; Shishido, K. Tetrahedron 2011, 67, 3194. (b) Yoshida, M.; Maeyama, Y.; Al-Amin, M.; Hirai, Y.; Shishido, K. J. Org. Chem. 2011, 76, 5813. (c) Davies, P. W.; Martin, N. Org. Lett. 2009, 11, 2293. (d) Chen, D.-D.; Hou, X.-L.; Dai, L.-X. Tetrahedron Lett. 2009, 50, 6944.

(14) 4-Benzyl-2-methyl-1-tosyl-2,5-dihydro-1H-pyrrole (6a): Typical Procedure

A flame-dried $10 \mathrm{~mL}$ flask equipped with a stirrer bar was charged with vinyl aziridine $1 \mathrm{a}(46 \mathrm{mg}, 0.14 \mathrm{mmol}, 1.00$ equiv), (CuOTf) $)_{2}$-toluene ( $3.5 \mathrm{mg}, 0.007 \mathrm{mmol}, 0.05$ equiv), and THF ( 0.7 $\mathrm{mL}$ ), and the mixture was stirred for $2 \mathrm{~h}$ under argon at rt. The solvent evaporated under reduced pressure, and the crude product was purified by chromatography [silica gel, pentaneEtOAc (100:0 to 70:30)] to give a pale-yellow solid; yield: $28 \mathrm{mg}$ (60\%); $\mathrm{mp} 80-83^{\circ} \mathrm{C}$.

FTIR (neat): 1402, 1355, 1178, 1163, 1090, 993, 945, 858, 840, $765,664 \mathrm{~cm}^{-1} .{ }^{1} \mathrm{H}$ NMR $\left(400 \mathrm{MHz}, \mathrm{CDCl}_{3}\right): \delta=7.65-7.63(\mathrm{~m}, 2$ H), 7.27-7.20 (m, $5 \mathrm{H}), 7.01-6.99(\mathrm{~m}, 2 \mathrm{H}), 5.19-5.17(\mathrm{~m}, 1 \mathrm{H})$, 4.48-4.46 (m, 1 H), 4.04-3.90 (m, $2 \mathrm{H}), 3.33-3.23(\mathrm{~m}, 2 \mathrm{H}), 2.43$ $(\mathrm{s}, 3 \mathrm{H}), 1.38$ (d, $J=6.40 \mathrm{~Hz}, 3 \mathrm{H}) \cdot{ }^{13} \mathrm{C}$ NMR $\left(100 \mathrm{MHz}, \mathrm{CDCl}_{3}\right): \delta=$ 143.2, 137.6, 137.1, 134.8, 129.6 (2 C), 128.5 (2 C), 128.5 (2 C), 127.4 (2 C), 126.5, 126.3, 63.4, 56.6, 35.1, 22.9, 21.5. HRMSASAP: $m / z[\mathrm{M}+\mathrm{H}]^{+}$calcd for $\mathrm{C}_{19} \mathrm{H}_{22} \mathrm{NO}_{2} \mathrm{~S}$ : 328.1371 ; found: 328.1381 . 